\title{
Optical Measurements of Thermotropic Liquid Crystals
}

\author{
Tawfik A. El-Dessouki ${ }^{1}$, Mohammed Roushdy ${ }^{2}$, Nabil I. Hendawy ${ }^{3}$, \\ Magdi M. Naoum ${ }^{4}$, Ayman A. Zaki ${ }^{3 *}$ \\ ${ }^{1}$ Physics Department, Faculty of Science, Ain Shams University, Cairo, Egypt \\ ${ }^{2}$ Physics Department, Faculty of Science, Cairo University, Giza, Egypt \\ ${ }^{3}$ Physics Department, Faculty of Science, Benha University, Benha, Egypt \\ ${ }^{4}$ Chemistry Department, Faculty of Science, Cairo University, Giza, Egypt \\ Email: ${ }^{2}$ ayman_a73@hotmail.com
}

Received July 20, 2012; revised September 21, 2012; accepted November 6, 2012

\begin{abstract}
In this work, an experimental approach was used for measuring birefringence of thermotropic liquid crystal materials at different wavelengths in the visible region by using speckle interferometry. Also the values of the refractive indices were measured for these thermotropic liquid crystal materials in isotropic and liquid crystal phases at different wavelengths. Temperature dependency of the refractive indices for each LC sample at certain wavelengths was investigated in the isotropic and in LC phases.
\end{abstract}

Keywords: Thermotropic Liquid Crystal; Interference; Birefringence; Speckle Photography

\section{Introduction}

Substances that aren't as ordered as an ordered solid, but have some degree of alignment are properly called liquid crystals. The tendency of the liquid crystal molecules to point along the director leads to a condition known as anisotropy [1].

The birefringence of a liquid single crystal elastomer swollen with a low molecular weight liquid crystal was experimentally measured by polarizing microscopy as a function of temperature [2]. Another work describing a convenient and accurate technique for measuring the optical path difference induced by a birefringent crystal was given by electro-optic modulation [3]. Birefringence measurements at the wavelength $632.8 \mathrm{~nm}$ for some common nematic liquid crystal cells were studied [4].

New guidelines for selecting or synthesizing the liquid crystals with the desired birefringence were established [5]. The birefringence of the liquid crystal as a function of the temperature was measured with and without electric field. It was shown that the birefringence decreases with increase of temperature [6].

The tilt angle distribution of a nematic liquid crystal mixture doped with two anthraquinone derivatives having different molecular shapes was measured as a function of an external alternating applied voltage [7].

A scanning conoscopic method was used to measure the temperature dependence of the two indices $n_{e}, n_{o}$ and of the optical activity for uniaxial liquid crystals [8]. A theoretical and experimental approach for measuring

${ }^{*}$ Corresponding author. birefringence of anisotropic materials was described [9].

Each liquid crystal (LC) material has its own specific combination of structural moieties, which identify certain phase morphology, particular values of melting points and transition temperatures. Furthermore, the combination of structural moieties determines the physical properties of materials which are very important when they are considered for specific applications.

Five thermotropic LCs compounds locally prepared were investigated in this article. The structure of thermotropic liquid crystal materials used is 4-substituted phenyl4-alkoxy benzoates [10] which have the following structure:<smiles>[X]c1ccc(OC(=O)c2ccc(OCCC)cc2)cc1</smiles>

where $\mathrm{n}$ is an integer number, and $\mathrm{X}$ is the extension group which is varies from the electron-donating $\mathrm{CH}_{3} \mathrm{O}$ and the electron-withdrawing $\mathrm{NO}_{2}$, as shown in Table 1.

Table 1, shows the transition temperatures $\left({ }^{\circ} \mathrm{C}\right)$ for the used materials, where the symbols C-A, C-N, C-I, A-N, A-I, and N-I means the transitions from, solid crystal to semictic "A", solid crystal to nematic, solid crystal to isotropic, semictic " $A$ " to nematic, semictic " $A$ " to isotropic and nematic to isotropic respectively.

\section{Experimental Measurement of Refractive Index by Abbe Refractometer}

Abbe refractometer equipped circulating water bath around the prisms (Abbe "60" Refractometer Serial No. A87067, type of instrument, standard 60/70) was used for measuring refractive indices of the LCs at different 
wavelengths and different temperatures. The temperature of water was controlled by a thermostat within $\pm 0.1^{\circ} \mathrm{C}$. A white light source was used with interference filters of wavelengths $(638.3 \mathrm{~nm}, 577 \mathrm{~nm}, 546 \mathrm{~nm}, 435.8 \mathrm{~nm})$, and sodium spectral lamp of wavelength $(589.3 \mathrm{~nm})$. The dispersion relations between the refractive indices and the wavelengths at certain temperature in their isotropic phase and liquid crystal phase for samples I $6_{a}$, I $8_{a}$, I $6_{e}$, I $8_{\mathrm{e}}$, and $\mathrm{I} 14_{\mathrm{e}}$ are shown in Figures 1-5.

The values of refractive indices of the thermotropic LC materials were determined also by using the spectrophotometer device (The Lambda 3 Double-Beam UVvisible spectrophotometer) which is available in 190 to $750 \mathrm{~nm}$ or 190 to $900 \mathrm{~nm}$ wavelength ranges and accept a full complement of accessories. This device was modified for heating the sample by using controlled electric oven. The value of refractive index was determined by measuring the reflectance values of material [11]. A slight difference in the accuracy of the values of refractive indices was noticed between $\approx 0.001$ to $\approx 0.01$, when comparing results between values measured by the Abbe refractometer and the spectrophotometric technique.

\section{Measurements of Birefringence by Speckle Photographic Technique}

Speckle interferometry technique was used to measure birefringence of the LCs. The optical setup used is shown in Figure 6. The samples were put into an electric oven for measuring birefringence at a certain temperature. The interference pattern for both ordinary and extraordinary components were magnified by $q / p$, where $p$ is the distance from the lens to the object reduced by the term $t$ $(1-\mathrm{n})$, and $\mathrm{q}$ is the distance from the lens to the image; $t$ is the thickness of the liquid crystal whose refractive index is $n$. The photographs were taken on heating and cooling cycles. Interference Young fringes from the specklegram for sample "I 8 " at laser source of wave-length $632.8 \mathrm{~nm}$ is shown in Plate $\mathbf{1}$.

The relationship of the shift " $D$ " between ordinary, extraordinary images and the spacing of the Young fringes " $\Lambda$ " is given by [12]:

$$
D=f \lambda\left(\frac{p}{q \Lambda}\right)
$$

Table 1. The transition temperatures $\left({ }^{\circ} \mathrm{C}\right)$ for compounds the LC materials used. The values between parentheses are those determined by the extrapolation method.

\begin{tabular}{|c|c|c|c|c|c|c|c|c|}
\hline compound & $N$ & $\mathrm{X}$ & $\mathrm{T}_{\mathrm{C}-\mathrm{A}}\left({ }^{\circ} \mathrm{C}\right)$ & $\mathrm{T}_{\mathrm{C}-\mathrm{N}}\left({ }^{\circ} \mathrm{C}\right)$ & $\mathrm{T}_{\mathrm{C}-\mathrm{I}}\left({ }^{\circ} \mathrm{C}\right)$ & $\mathrm{T}_{\mathrm{A}-\mathrm{N}}\left({ }^{\circ} \mathrm{C}\right)$ & $\mathrm{T}_{\mathrm{A}-\mathrm{I}}\left({ }^{\circ} \mathrm{C}\right)$ & $\mathrm{T}_{\mathrm{N}-\mathrm{I}}\left({ }^{\circ} \mathrm{C}\right)$ \\
\hline I $6 a$ & 6 & $\mathrm{CH}_{3} \mathrm{O}$ & - & - & 95.0 & - & - & $(71.2)$ \\
\hline I 8 a & 8 & $\mathrm{CH}_{3} \mathrm{O}$ & - & - & 85.0 & - & - & $(76.2)$ \\
\hline I $6_{e}$ & 6 & $\mathrm{NO}_{2}$ & - & - & 68.0 & - & - & $(58.5)$ \\
\hline I 8 e & 8 & $\mathrm{NO}_{2}$ & 53.1 & - & - & 62.6 & - & 69.2 \\
\hline I $14_{\mathrm{e}}$ & 14 & $\mathrm{NO}_{2}$ & 74.6 & - & - & - & 87.9 & - \\
\hline
\end{tabular}

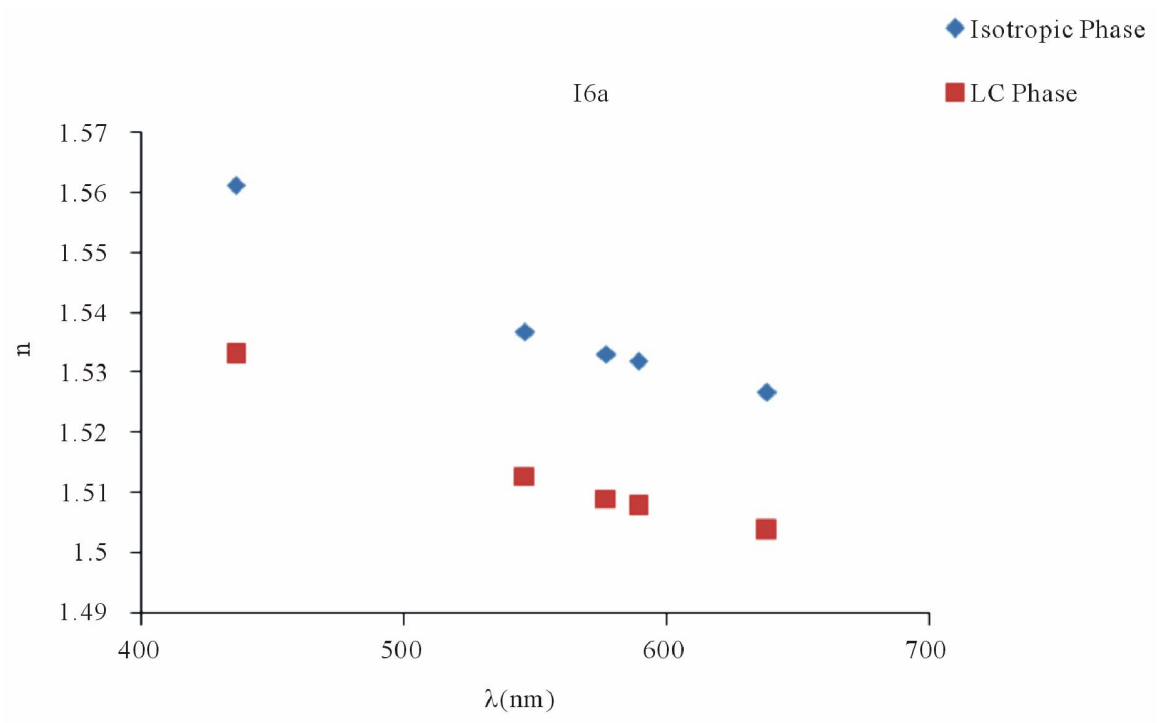

Figure 1. Dependence of the refractive index (n) on wavelength $(\lambda)$ at given temperatures, $\mathrm{T}=75^{\circ} \mathrm{C}, 80^{\circ} \mathrm{C}$ in isotropic phase, and $70^{\circ} \mathrm{C}, 65^{\circ} \mathrm{C}$ in $\mathrm{LC}$ phase for $I 6_{\mathrm{a}}$ liquid crystal. 
I8a Isotropic Phase

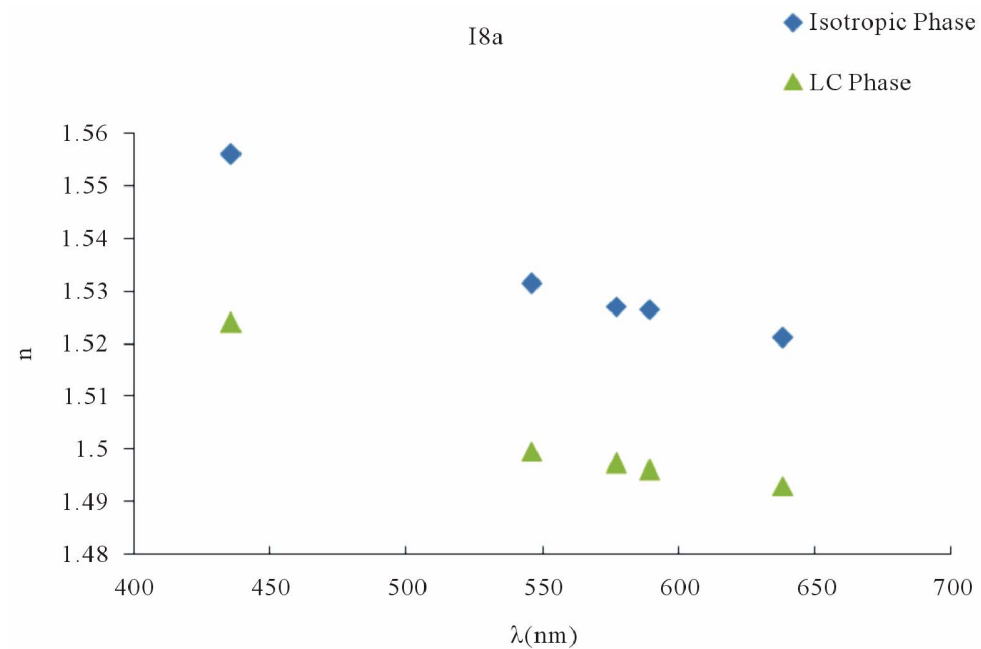

Figure 2. The relation between refractive index $(\mathrm{n})$ and wavelength $(\lambda)$ at certain temperature, $\mathrm{T}=85^{\circ} \mathrm{C}, 90^{\circ} \mathrm{C}$ in isotropic phase, and $75^{\circ} \mathrm{C}, 70^{\circ} \mathrm{C}$ in LC phase for (I 8a) liquid crystal.

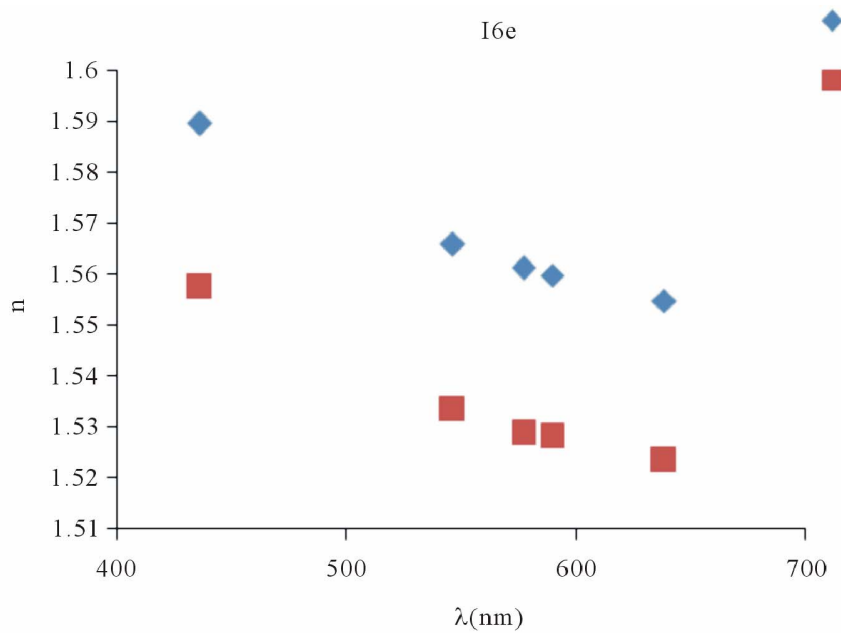

Figure 3. The dispersion relation between refractive index $(\mathrm{n})$ and wavelength $(\lambda)$ at certain temperature, $\mathrm{T}=60^{\circ} \mathrm{C}, 65^{\circ} \mathrm{C}$ in isotropic phase and $55^{\circ} \mathrm{C}, 50^{\circ} \mathrm{C}$ in LCs phase for I 6 liquid crystal.

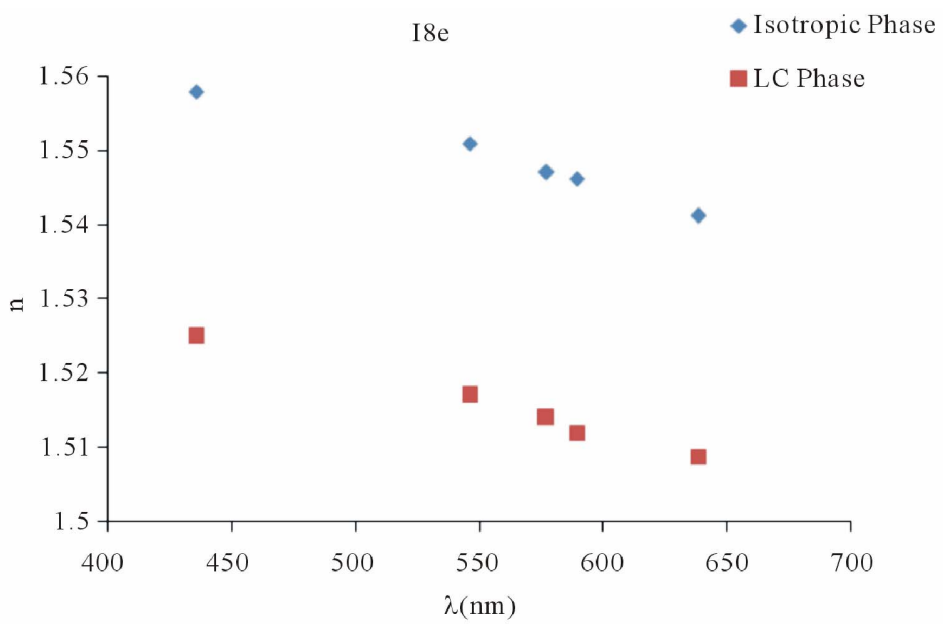

Figure 4. The dispersion relation between refractive index (n) and wavelength $\mathrm{l}(\mathrm{nm})$ at certain temperature, $\mathrm{T}=70^{\circ} \mathrm{C}, 75^{\circ} \mathrm{C}$ in isotropic phase and $\mathrm{T}=65^{\circ} \mathrm{C}, 60^{\circ} \mathrm{C}$ in $\mathrm{LC}$ phase for $\mathrm{I} 8_{\mathrm{e}}$ liquid crystal. 


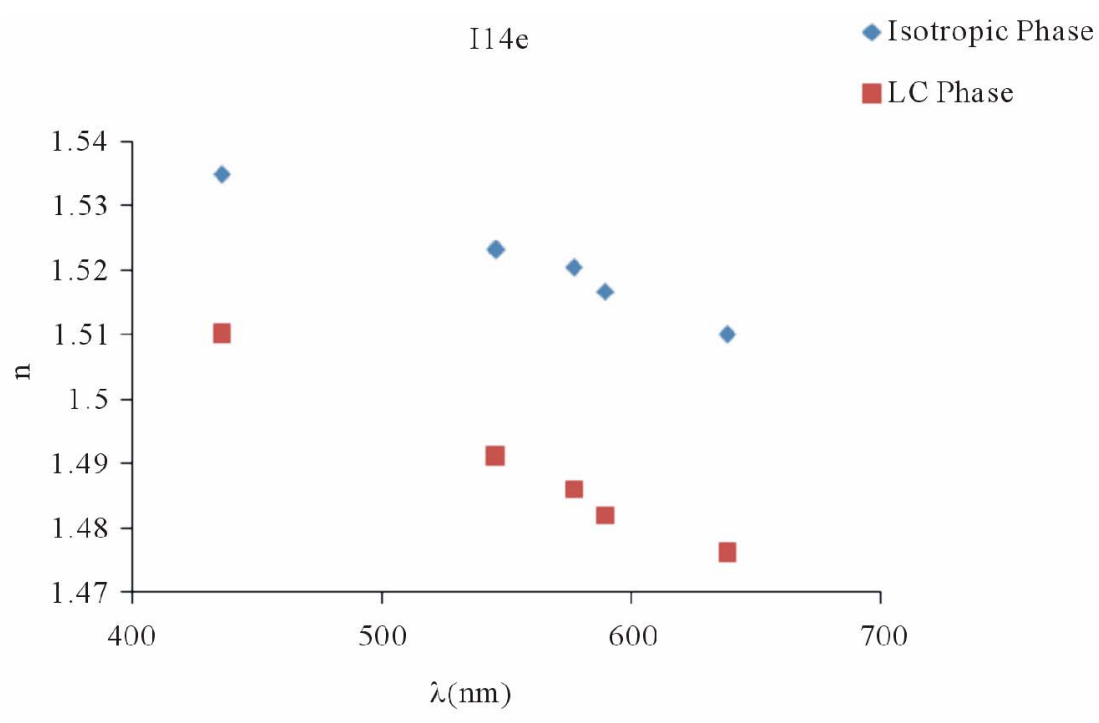

Figure 5. The dispersion relation between refractive index (n) and wavelength $(\lambda \mathrm{nm})$ at certain temperature, $\mathrm{T}=86^{\circ} \mathrm{C}, 92^{\circ} \mathrm{C}$ in isotropic phase and $84^{\circ} \mathrm{C}, 78^{\circ} \mathrm{C}$ in $\mathrm{LC}$ phase for $\mathrm{I} 14_{\mathrm{e}}$ liquid crystal.

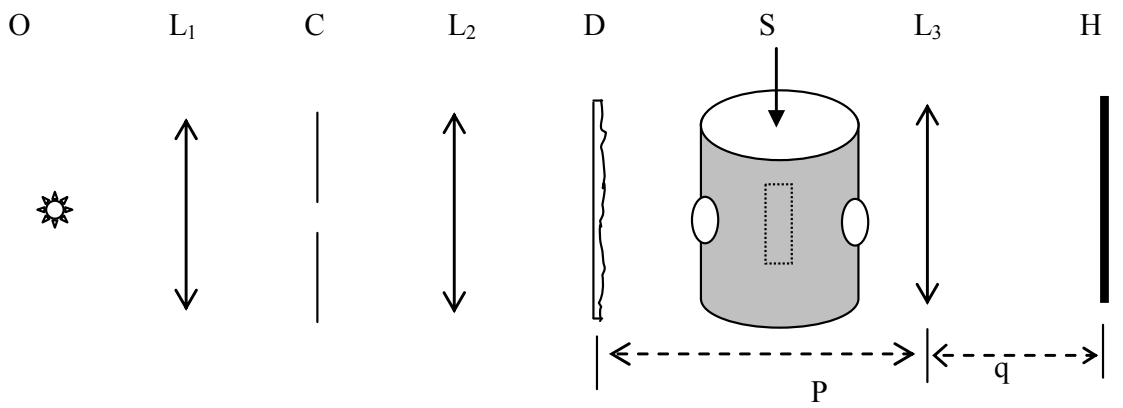

Figure 6. Optical set-up for measuring the birefringence of an anisotropic optical material. O: monochromatic source, L1, L2 \& L3: converging lenses, C: diaphragm, D: diffuser, S: liquid crystal inside the oven and H: holographic plate.

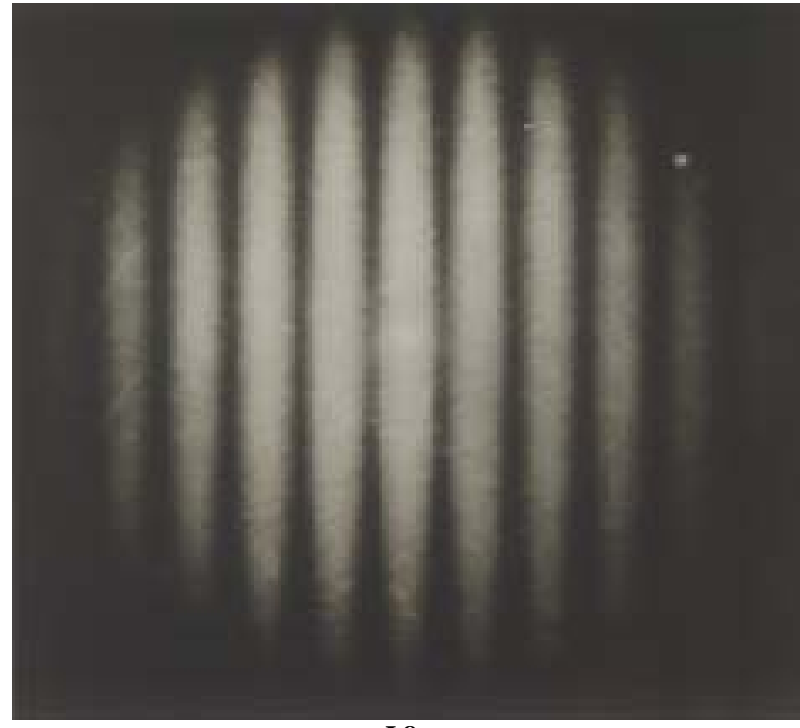

I 8

Plate 1. The interference Young's fringes from specklegram for I $8_{a}$, thermotropic liquid crystal with laser source of wavelength $632.8 \mathrm{~nm}$. where, $f$ is the focal length of the Fourier transform lens used for the observation of Young's fringes from the specklegram. In order to calculate birefringence $\Delta \mathrm{n}$ of liquid crystal, the following equation was used [13]:

$$
\frac{\Delta \mathrm{n}}{\mathrm{n}} \approx \frac{\lambda f}{t \sin 2 \theta}\left(\frac{p}{q \Lambda}\right) .
$$

where $\mathrm{n}$ is the refractive index of the LC; $t$ is the thickness of the sample and $\theta$ is the angle between the optic axis and the normal to the surface of the sample. The angle $\theta$ was determined using the conoscopic measurement system.

\section{Conoscopic Measurement}

A layer of the LC material is sandwiched between two glass plates in order to produce a tilted parallel homogeneous orientation. Hence the resulting structure behaves like the optically uniaxial crystal, and the problem was simply to determine the angle of the optic axis to the glass panels. By examining the specimen with a polarizing 
microscope in convergent light between crossed polarizers, the information concerning the orientation of the optic axis of the crystal was obtained [14,15].

Table 2 shows the measured data for LCs used where birefringence was calculated with laser sources of wavelengths, $632.8 \mathrm{~nm}, 543.5 \mathrm{~nm}, 514.5 \mathrm{~nm}$, and $488 \mathrm{~nm}$, and the thickness of each sample was $150 \mu \mathrm{m}$.

The dispersion curves for birefringence in the visible region are shown in Figure 7. This figure shows that the values of birefringence were increased by increasing the number of carbon atoms in the terminal alkoxy chain, i.e. increase of molecular length. Also the birefringence of LCs I $8_{\mathrm{a}}$ and I $6_{\mathrm{a}}$, which bear the terminal $\left(\mathrm{OCH}_{3}\right)$ group, are greater than for I $8_{\mathrm{e}}$ and $\mathrm{I} 6_{\mathrm{e}}$, which were ended by the $\left(\mathrm{NO}_{2}\right)$ group. These figures show that $\Delta \mathrm{n}$ is inversely proportional to $\lambda$ which is in opposition with the direct relation given by Equation (2), so that the thermotropic LCs used have negative birefringence.

Temperature dependency of the refractive indices for each LC sample at certain wavelengths was obtained in the isotropic and in LC phases as shown in Figures 8-12. These relations showed inverse proportionally between the refractive indices and wavelengths, in isotropic region and direct proportionally in LC region.

To explain this behavior, the molecules of LC materials (Figure 13, shows a director of molecule) in close contact with the glass plates are oriented parallel to the plate and at the same time the inner molecules are oriented approximately parallel to them. The incident beam is perpendicular to the molecule director as in Figure 14(a). With increasing the temperature the mobility of the molecules increases and their orientations change as in Figure 14(b) and the optical path of the light inside the molecule increases. By further increase of temperature the molecules will be oriented parallel to the incident beam and then we get a maximum optical path inside the molecules as in Figure 14(c). As a result of this long path the speed of light beam decreases, hence the value of refractive index increases, which interpret why refractive index increases with increasing temperature in LC phase.

The phenomenon of the change in refractive indices with temperatures for these liquid crystal materials makes it possible to be used as a thermometer in this

Table 2. The values of birefringence $\Delta \mathbf{n}$ at different wavelengths for different thermotropic liquid crystal materials used.

\begin{tabular}{rcccc}
\hline & \multicolumn{2}{c}{$\mathrm{n}$} \\
\hline Sample & $(\lambda)(632.8 \mathrm{~nm})($ Error $= \pm 0.01)$ & $(\lambda)(543.5 \mathrm{~nm})($ Error $= \pm 0.01)$ & $(\lambda)(514.5 \mathrm{~nm})($ Error $= \pm 0.01)$ & $(\lambda)(488 \mathrm{~nm})($ Error $= \pm 0.01)$ \\
$6 \mathrm{a}$ & 0.24 & 0.26 & 0.27 & 0.28 \\
$8 \mathrm{a}$ & 0.31 & 0.32 & 0.33 & 0.34 \\
$6 \mathrm{e}$ & 0.21 & 0.22 & 0.23 & 0.24 \\
$8 \mathrm{e}$ & 0.23 & 0.25 & 0.26 & 0.27 \\
$14 \mathrm{e}$ & 0.27 & 0.28 & 0.29 & 0.30 \\
\hline
\end{tabular}

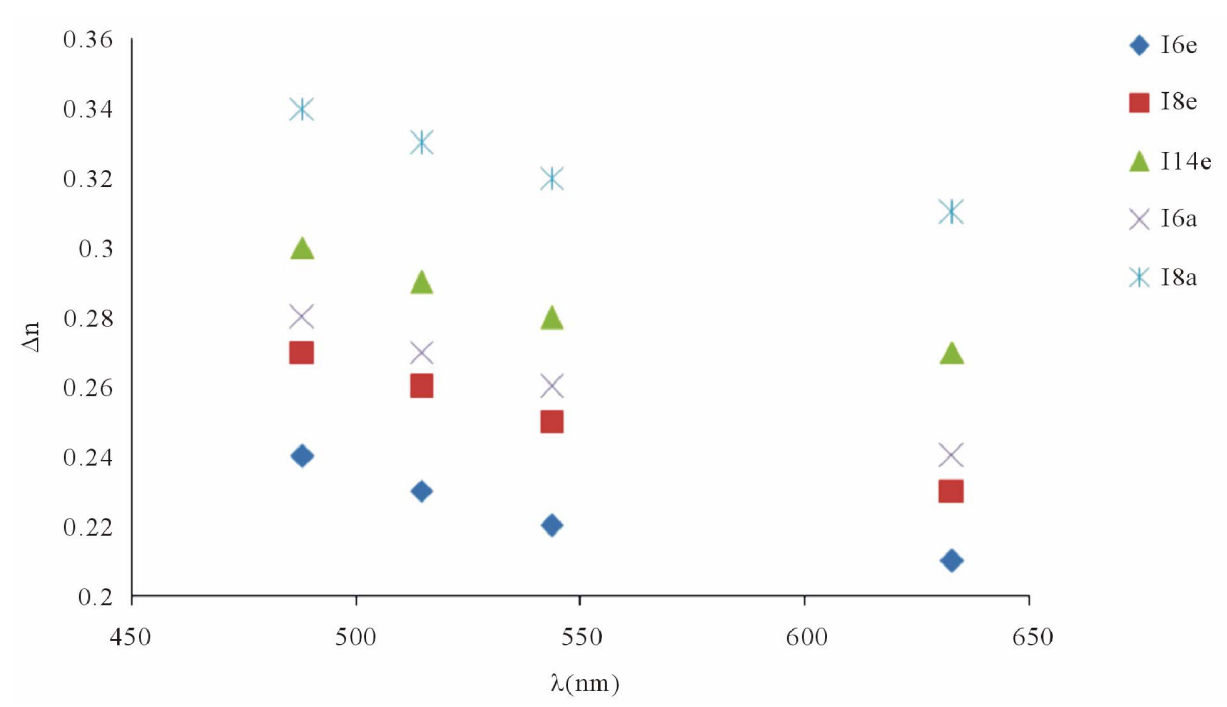

Figure 7. The dispersion relation between birefringence $(\Delta \mathrm{n})$ and the wavelength $(\lambda \mathrm{nm})$ at a certain temperature, in LC phase for (I $6_{a}$, I $8_{a}, I 6_{e}$, I $8_{e}$, and I 14 ) liquid crystals used. 


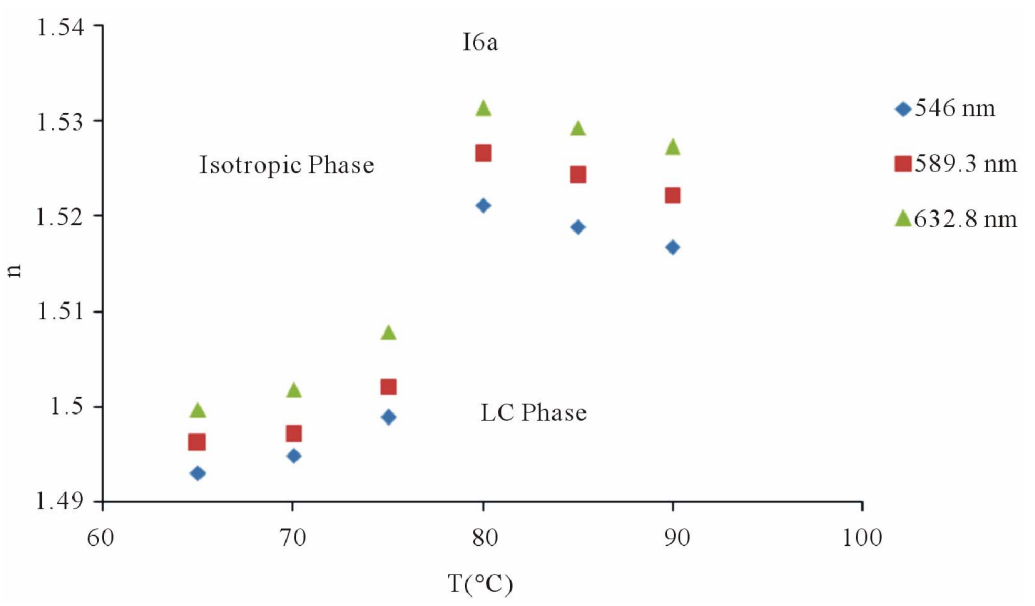

Figure 8. Dependence of refractive indices on temperatures at certain wavelengths, $546 \mathrm{~nm}, 577 \mathrm{~nm}, 589.3 \mathrm{~nm}$, and $638.3 \mathrm{~nm}$, for sample I $6_{\mathbf{a}}$.

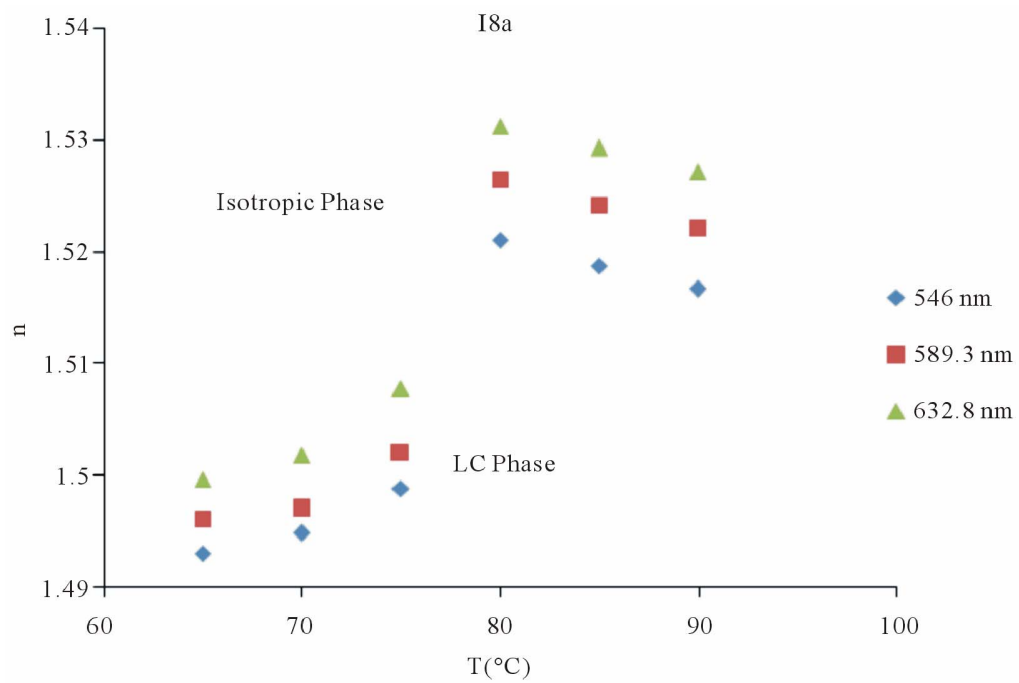

Figure 9. Dependence of refractive indices on temperatures at certain wavelengths, $546 \mathrm{~nm}, 589.3 \mathrm{~nm}$, and $638.3 \mathrm{~nm}$, for sample I $8_{\mathrm{a}}$.

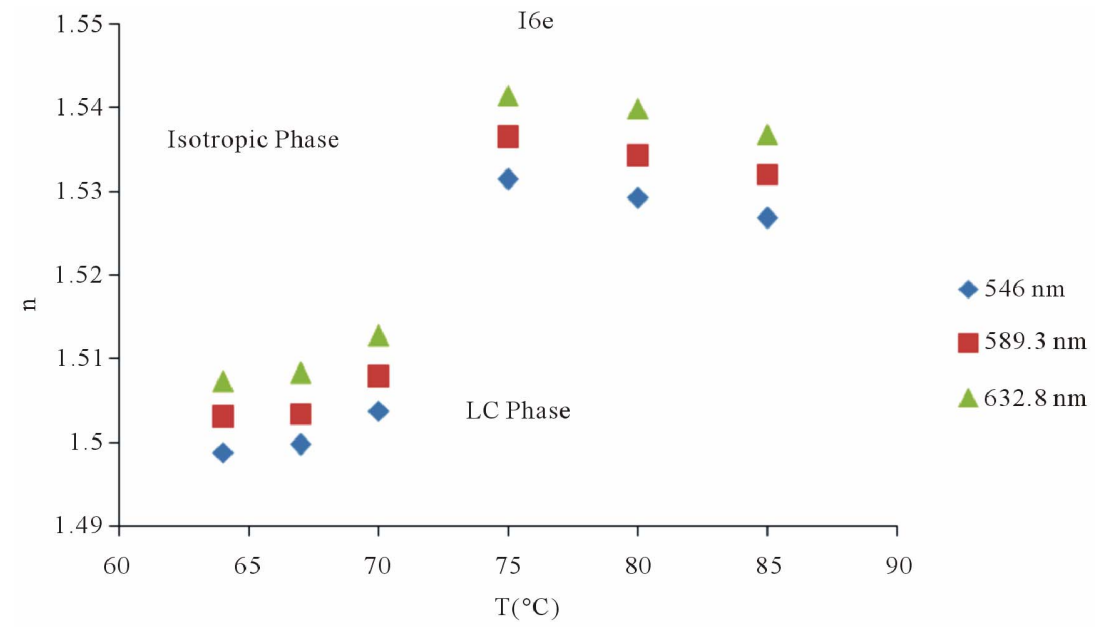

Figure 10. Dependence of refractive indices on temperatures at certain wavelengths, $546 \mathrm{~nm}, 577 \mathrm{~nm}, 589.3 \mathrm{~nm}$, and $638.3 \mathrm{~nm}$, for sample I $\mathbf{6}_{\mathrm{e}}$. 


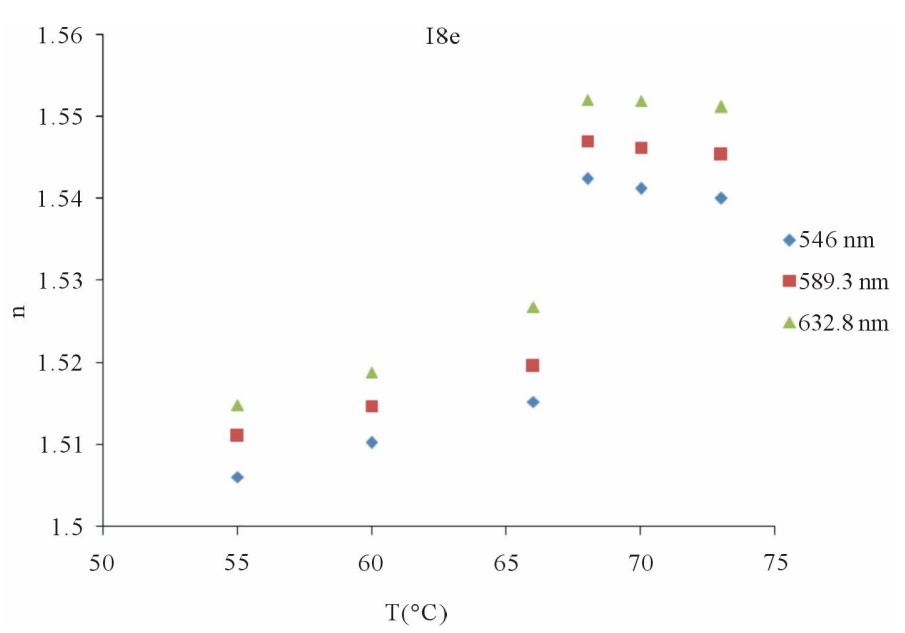

Figure 11. Dependence of refractive indices on temperatures at certain wavelengths, $546 \mathrm{~nm}, 589.3 \mathrm{~nm}$, and $638.3 \mathrm{~nm}$, for I $8_{\mathrm{e}}$ sample.

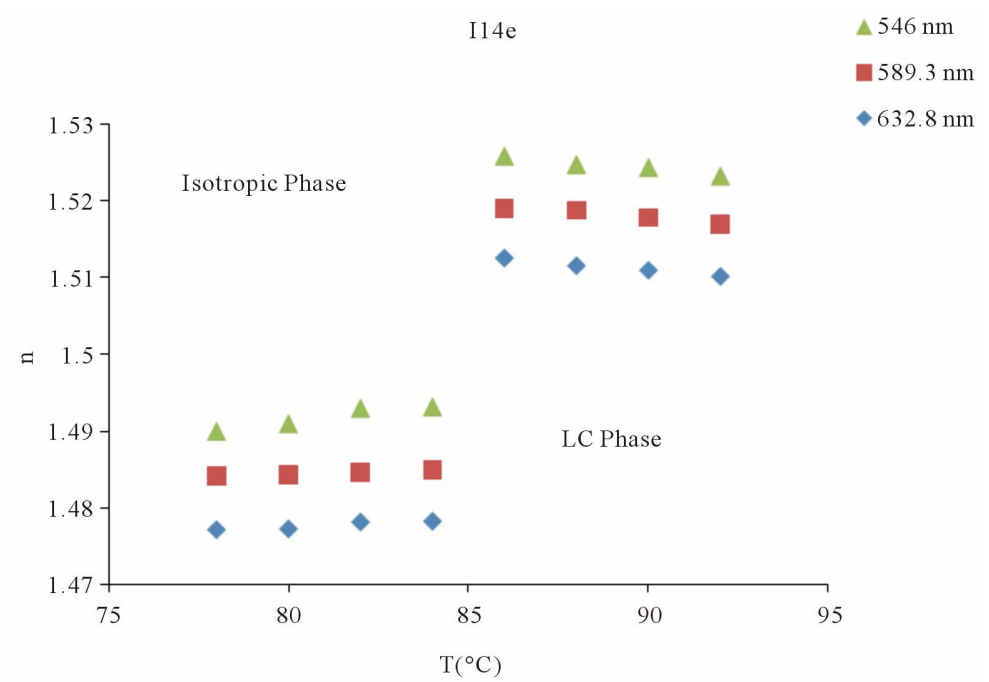

Figure 12. Dependence of refractive indices and temperatures at certain wavelengths, $546 \mathrm{~nm}, 577 \mathrm{~nm}, 589.3 \mathrm{~nm}$, and 638.3 nm, for I 14 sample.

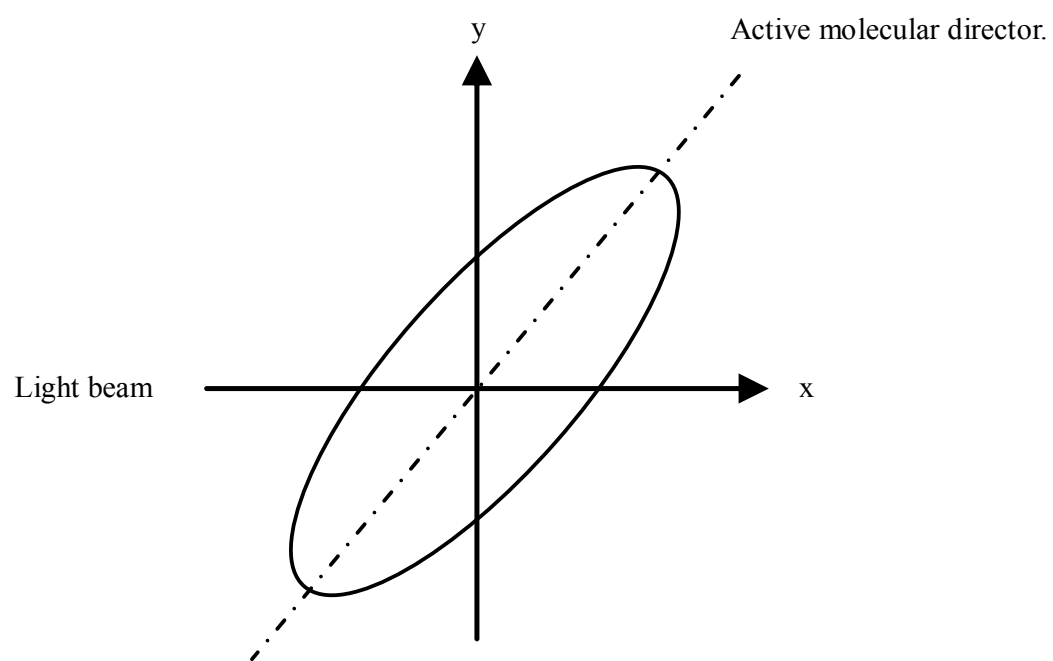

Figure 13. The optical path in $x$-, $y$-directions through a liquid crystal material when rotated under the effect of temperature. 


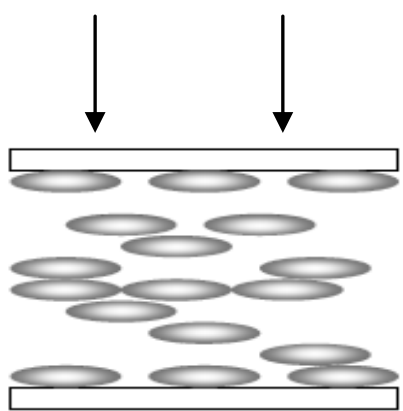

(a)

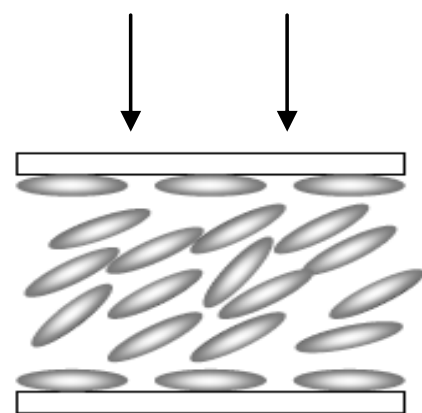

(b)

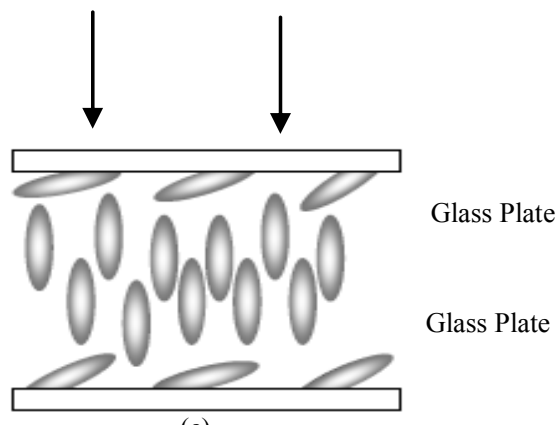

(c)

Figure 14. LC molecular ordering as a function of heating. Molecular orientation in a liquid crystal device: (a) At equilibrium with no heat; (b) with a slight increase of heat; (c) at equilibrium with a high increase of heat.

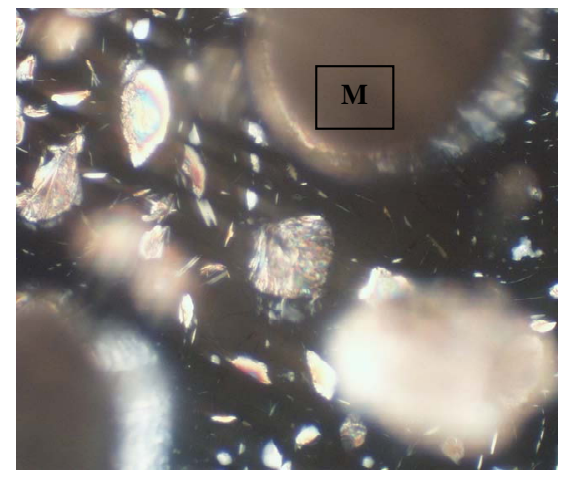

$6_{\mathrm{a}}(40 \times)$

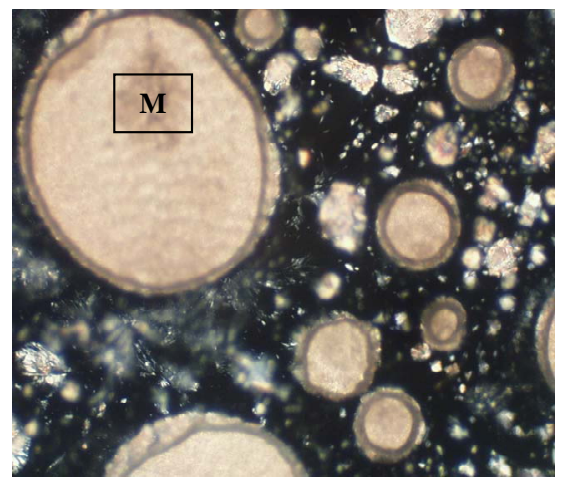

8 a $(40 \times)$

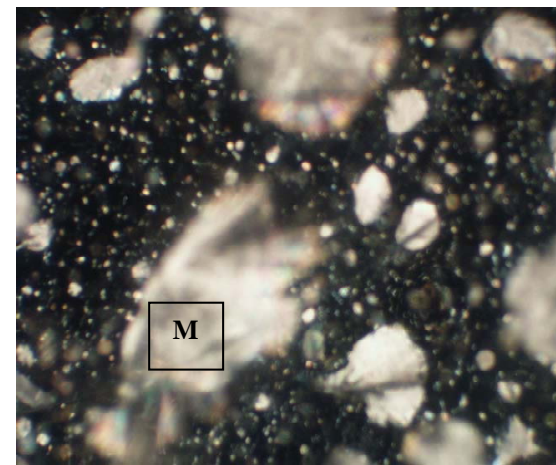

$6_{\mathrm{e}}(40 \times)$

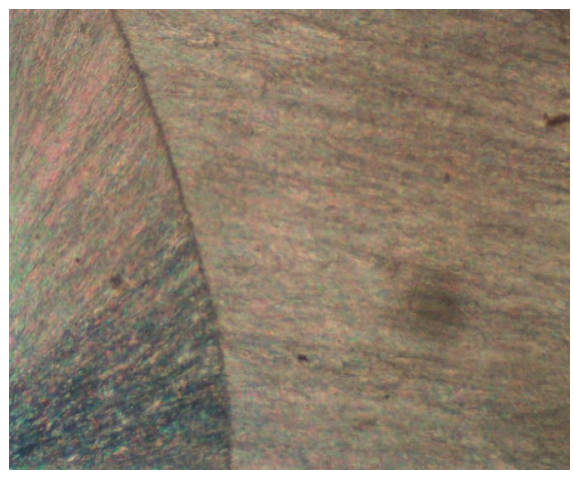

M of $6_{\mathrm{a}}(100 \times)$

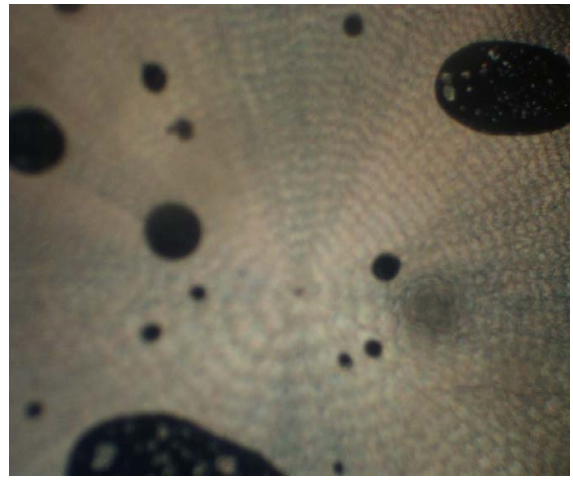

M of $8 \mathrm{a}(100 \times)$

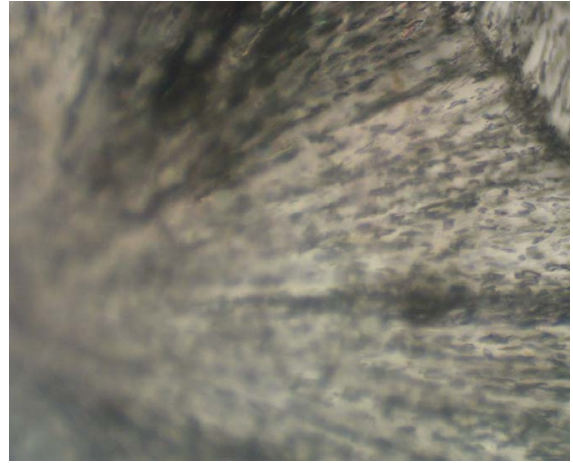

M of $6_{e}(100 \times)$

Plate 2. The microscopic pictures for the crystalline phase of I $6_{a}$, I $8_{a}$, and I $6_{e}$ liquid crystal materials under white light source (The sample is between crossed polarizers). 


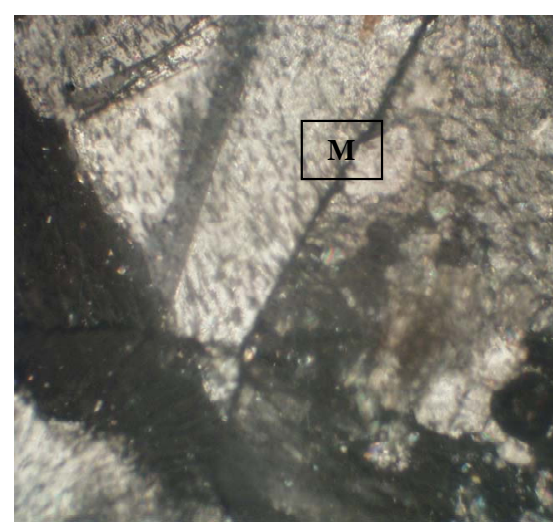

$8_{\mathrm{e}}(40 \times)$

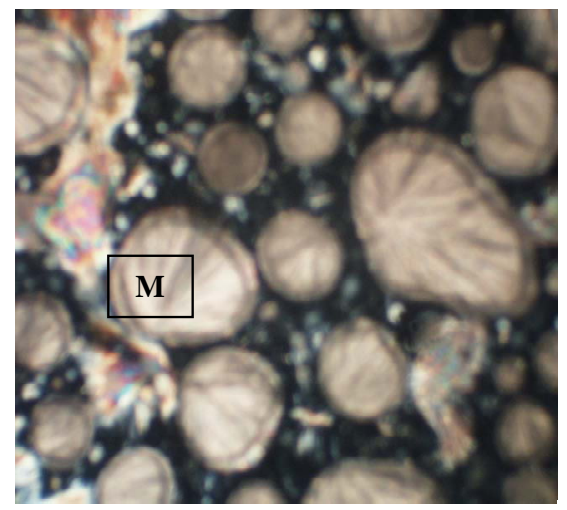

$14_{\mathrm{e}}(40 \times)$

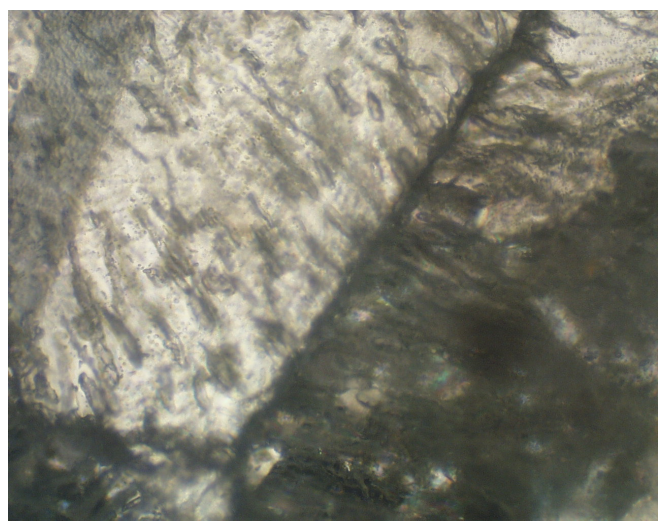

M of $8_{e}(100 \times)$

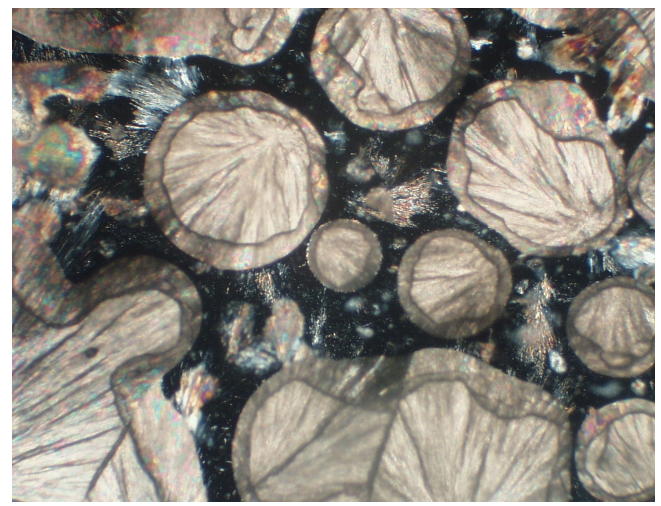

M of $14_{e}(100 \times)$

Plate 3. The microscopic pictures for the crystalline phase of I $8_{\mathrm{e}}$ and $\mathrm{I} 14_{\mathrm{e}}$ liquid crystal materials under white light source (The sample is between crossed polarizers).

region of temperature and displays the temperature of its environment by the reflected color. It is also can be used to create sensors with a wide variety of responses to the temperature change.

When the solid material is solidified at room temperature $\left(23^{\circ} \mathrm{C}\right)$, it has a white color with different phases of aggregations. When the samples of I $6_{a}, I$ I $6_{e}, I 8_{a}$, I $8_{e}$ and I $14_{\mathrm{e}}$ are placed polarizing microscope, Plates 2 and 3 were observed. The bright and dark areas are the resultant intensity distribution of the samples due to interference of polarized light. Different colors which are viewed between crossed polarizers correspond also to different twist states.

\section{Conclusion}

The values of refractive indices and birefringence for the thermotropic liquid crystal materials used were obtained with an acceptable degree of accuracy. The values of birefringence where found to increase by increasing the number of carbon atoms in terminal alkoxy group. Also the birefringence of samples ended by the $\left(\mathrm{OCH}_{3}\right)$ group, were found to be greater than for those ended by the $\left(\mathrm{NO}_{2}\right)$ group. The dispersion relation between birefrin- gence and different wavelengths in the visible spectrum were determined. The relation between refractive index and temperature at different wavelengths for thermotropic LCs used was studied and interpreted by considering that the kinetic energy of the molecules increases and their orientations change with increase of temperature, and due to this change the optical path of the light inside the molecule increases.

\section{REFERENCES}

[1] A. Roshi, "Quenched Random Disorder Studies in Liquid Crystal and Aerosil Dispersions," Faculty of the Worcester Polytechnic Institute, Worcester, 2005.

[2] Y. Yusril, S. Yusuke and K. Shoichi, "Birefringence Measurement of Liquid Single Crystal Elastomer Swollen with Low Molecular Weight Liquid Crystal," Chemical Physics Letters, Vol. 382, No. 1, 2003, pp. 198-202.

[3] B. Badr-Eddine, H. El-Houssine, Z. Qin and V. Bruno, "An Electro-Optic Modulation Technique for Direct and Accurate Measurement of Birefringence," Optical Communication, Vol. 221, No. 4-6, 2003, pp. 271-278.

[4] T. Beica, R. Moldovan, M. Tintaru, I. Enache and S. Frunza, "Measurements of Optical Anisotropy of A Ca- 
lamitic Lyotropic Liquid Crystal," Crystal Research and Technology, Vol. 39, No. 2, 2004, pp. 151-156. doi:10.1002/crat.200310163

[5] M. Manaia, A. Gharbia, J. P. Marceroub, H. T. Nguyenb and J. C. Rouillonb, "Optic and Electro-Optic Investigations on $\mathrm{SmQ}, \mathrm{SmC}_{\mathrm{A}}$ and $\mathrm{L}$ Phases in Highly Chiral Compounds," Physica B, Vol. 368, No. 1-4, 2005, pp. 168-178.

[6] Z. L. Cao, L. Xuan, L. F. Hu, X. H. Lu and Q. Q. Mu, "Temperature Effect on the Diffraction Efficiency of the Liquid Crystal Spatial Light Modulator," Optics Communications, Vol. 267, No. 1, 2006, pp. 69-73. doi:10.1016/j.optcom.2006.06.003

[7] A. Jafari, A. Ghanadzadeh, H. Tajalli and M. Yeganeh, "Linear Optical Oarameters of a Dyed Nematic Mixture in the Presence of an ac Voltage," Optical Materials, Vol. 29, No. 8, 2007, pp. 1004-1009. doi:10.1016/j.optmat.2006.03.034

[8] N. Bitri, A. Gharbi and J. P. Marcerou, "Scanning Conoscopy Measurement of the Optical Properties of Chiral Smectic Liquid Crystals," Physica B: Condensed Matter, Vol. 403, No. 21-22, 2008, pp. 3921-3927. doi:10.1016/i.physb.2008.07.033

[9] T. A. El-Dessouki, N. I. Hendawy and A. A. Zaki, "Measuring Birefringence of Curved Sheet and Single Crystals by Double-Exposure Speckle Photography," Optics and Lasers in Engineering, Vol. 47, No. 6, 2009, pp.
622-628.

doi:10.1016/j.optlaseng.2008.12.006

[10] R. I. Nessim, "Phase Behaviour of Binary Mixture of 4Substituted Phenyl 4'-N-Alkoxybenzoates," Liquid Crystals, Vol. 30, No. 2, 2003, pp. 211-218. doi:10.1080/0267829021000060241

[11] E. Hecht and A. Zajac, “Optics,” Addison-Wesley, Reading, 1990.

[12] M. Francon, "Information Processing Using Speckle Patterns," In: J. C. Dainty, Ed., Laser Speckle and Related Phenomena, Springer-Verlag, New York, 1975, pp. 171201. doi:10.1007/BFb0111439

[13] L. M. Bernardo and O. D. D. Soares, "Birefringence Measurements by Double Speckle Photography," Applied Optics, Vol. 26, 1987, pp. 769-772. doi:10.1364/AO.26.0769 1

[14] W. A. Crossland, J. H. Morrissy and B. Needham, "Tilt Angle Measurements Of Nematic Phases Of Cyano- Biphenyls Aligned By Obliquely Evaporated Films," Journal of Physics D: Applied Physics, Vol. 9, No. 14, 1976, p. 2001.

[15] T. Fujikawa, K. Hiraok, et al., "Construction of Dynamic Conoscope Observation System Using CCD Camera And Image Processor," Japanese Journal of Applied Physics, Vol. 32, 1993, pp. 985-988. doi:10.1143/JJAP.32.985 